\title{
Vitamin B12, bone mineral density and fracture risk in adults: A systematic review
}

\author{
luciana Leal Gomes de Macêdo ${ }^{1 *}$, Cecilia Maria Resende Gonçalves de Carvalho², Janaína Costa Cavalcanti ${ }^{3}$, \\ Betania de Jesus e Silva de Almendra Freitas ${ }^{4}$ \\ ${ }^{1}$ MSc Student, Food and Nutrition Graduate Program, Universidade Federal do Piaú (PPGAN-UFPI), Teresina, PI, Brazil \\ 2Postdoctoral Degree in Nutrition and Public Health from Faculdade de Saúde Pública da Universidade de São Paulo (FSP/USP). Full Professor of Nutrition, UFPI, Teresina, PI, Brazil \\ ${ }^{3} \mathrm{MD}$, Geriatrician, Hospital Universitário da Universidade Federal do Piaú (HU-UFPI). Internal Medicine Residency Training Program at Hospital Regional da Asa Norte (HRAN) and Geriatric \\ Medicine Residency Program at Hospital Universitário da Universidade de Brasilia (HU-UnB), Teresina, PI, Brazil \\ ${ }^{4} \mathrm{PhD}$ in Medical Sciences from Universidade Estadual de Campinas (Unicamp). Associate Professor I of Nutrition, UFPI, Teresina, PI, Brazil
}

Study conducted by the Department of Nutrition, Universidade Federal do Piauí (UFPI), Teresina, PI, Brazil

Article received: $1 / 15 / 2017$ Accepted for publication: 3/12/2017

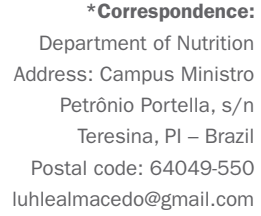

http://dx.doi.org/10.1590/1806-9282.63.09.801

\section{SUMmARY}

Objective: To consolidate information available on the effect of vitamin B12 on bone mineral density and fracture risk, with emphasis on clinical trials, observational and longitudinal data conducted in humans.

Method: A systematic review of the literature of the past decade on the role of vitamin B12 in bone mineral density and fracture risk in subjects of all ages and both sexes was performed by means of a PubMed, Science Direct, Medline and SciELO database search. Articles included in this review were identified using the search terms: B12 Vitamin and Bone Mineral Density and Vitamin B12 and Risk of Fractures. Evidence quality of the included articles was evaluated by GRADE system.

Results: A total of 25 original studies were identified. After reviewing the titles and abstracts of articles, only 17 articles met the inclusion criteria. The present review provides evidence that the role of vitamin B12 on bone mineral density or fracture risk should be further elucidated. Controversies are explained by heterogeneity of methodologies used for the diagnosis of vitamin B12 and also by differences among populations investigated on the studies.

Conclusion: A real effect of vitamin B12 deficiency in bone health and the mechanisms associated with bone metabolism is not well established yet. It is extremely important to carry out more clarifying studies about this theme, especially with vulnerable groups such as postmenopausal and elderly women, as is well-known that they are greatly affected by deficiency of this vitamin.

Keywords: bone health vitamin, B12 vitamin supplementation, fracture risk.

\section{INTRODUCTION}

Osteoporosis is an important public health issue that can worsen over the years and increase financial spending within the context of a worldwide trend of increased life expectancy. This is a chronic, multifactorial disease, characterized by a decrease in bone mineral density and deterioration of the skeletal structure microarchitecture, leading to fragility and increased susceptibility to fractures. ${ }^{1}$

Several factors are associated with the etiology of bone mass loss, some of them having a nutritional origin. It is well established that preventive strategies such as calcium and vitamin D supplementation associated with regular physical activity decrease the incidence of fractures and increase bone mineral density. ${ }^{2}$

It is thus very important to identify risk factors for osteoporosis and to adopt interventions that may reduce the likelihood of fracture, assisting individuals who may benefit from faster screening for osteoporosis, thereby avoiding its negative repercussions regarding health and quality of life.

Some studies on the promotion of bone health have demonstrated the involvement of vitamin B12 in the quality of bone structure in humans. ${ }^{3-5}$ The mechanism of action of this vitamin in the microarchitecture of bones is not yet 
well characterized, but it seems to modulate the formation of collagen or alter the metabolism of osteoblasts, always in a dose-dependent manner. ${ }^{6,7}$ Low levels of vitamin B12 increase the risk of reduced bone mineral density and fractures $^{8,9}$ in these individuals. However, the results are not yet conclusive and the actual impact of vitamin B12 deficiency on bone health and the mechanisms associated with bone metabolism is not well established.

Recent research has shown an association between vitamin B12 deficiency and increased risk of low bone mineral density, while other studies do not present consistent results. ${ }^{7-9}$

In this context, our main objective in this review is to consolidate the available information about the effects of vitamin B12 on bone mineral density and fracture risk, obtained mainly from clinical trials, observational data and longitudinal studies conducted in humans.

\section{Method}

Our study consists of a systematic review of literature, with search for articles in the following electronic databases: National Library of Medicine (PubMed), Science Direct, Medical Literature Analysis and Retrieval System Online (Medline) and Scielo. The bibliographic search was carried out between May and July, 2016. As a data search strategy, we included descriptors restricted to the "title," "summary" and "article descriptors" (mesh terms) fields: B12 Vitamin and Bone Mineral Density and B12 Vitamin and Risk of Fractures.

We included articles from the past ten years, written in English, Spanish and Portuguese, which evaluated the role of vitamin B12 on bone mineral density in populations of all ages and both sexes, including original articles/research that made the full version of the article available. Editorials, letters to the reader, review articles, articles that did not offer access to complete content, and those that were published in other foreign languages were excluded, as well as those assessing the role of vitamin B12 in other disorders such as dementia, myasthenia, and more.

Aiming at the adequate methodological quality of the systematic review, the selection was performed by three independent evaluators, strictly following the inclusion and exclusion criteria. The articles were evaluated first by title and then by abstract, and disagreements were resolved by consensus among researchers. The reference list of the articles identified in the electronic search was also reviewed in order to find studies that could contribute significantly to our review of the literature.

To grade the quality of the evidence and the strength of the recommendations found in the results of the articles included in our review, we used the GRADE (Grading of Recommendations Assessment, Development and Evaluation) system, adopted by the Cochrane Collaboration. In the GRADE system, the quality of evidence is classified into four levels: high, moderate, low and very low. ${ }^{10}$

\section{Results}

In all, 2,529 articles were identified through search in electronic databases; 1,612 were excluded based on the initial criteria (publications written in the past 10 years in English, Spanish or Portuguese, with full text available). Of the remaining 917 articles, 892 were eliminated, as they did not include longitudinal or observational studies, or case-control studies performed in humans. Thus, 25 full texts were examined and 17 were included in our review. Of these, eight studies were excluded: one was a systematic review with meta-analysis; another study evaluated only markers of bone remodeling; and in six studies the bone mineral density and/or risk of fractures of the individuals was not investigated (Figure 1).

Overall, six longitudinal studies, nine cross-sectional studies and two randomized, double-blind, placebo-controlled clinical trials evaluating BMD and/or fracture risk in adult humans were found. Chart 1 shows the main results and the quality of the evidence presented by the included studies.

\section{Discussion}

The association between bone health and vitamin B12 alone or with other B vitamins has been extensively studied in the most diverse populations, as shown in Chart 1. Our review provides evidence that the role of vitamin B12 in bone mineral density or fracture risk needs to be better elucidated.

Among the 17 studies analyzed in our systematic review, only three found an association between vitamin B12 and fracture risk and/or bone mineral density. Fourteen studies did not find such an association. The controversies are supported by the heterogeneity of the methods used to diagnose B12 hypovitaminosis, such as: investigation of dietary intake of vitamin B12, plasma or serum vitamin levels and analysis of methylmalonic acid. The populations participating in the studies analyzed also differed: Dutch, Brazilians, Americans, Norwegians, Britons, Danes, Turks, Germans, Croats and Chinese.

The first studies that related vitamin B12 to bone problems, such as BMD reduction and fractures, were performed in individuals with pernicious anemia. An increased risk of fractures was found among the study participants. ${ }^{11,12}$ 
Of the nine cross-sectional studies included in the present review, two found an association between vitamin B12 and BMD. Clarke et al. ${ }^{9}$ were the first to study the association between $B$ vitamins (dietary intake and serum levels) and BMD in patients with celiac disease aged over 20 years. A significant association was found only between serum levels of vitamin B12 and BMD in the hip and neck of the femur among men. No significant association between serum levels of vitamin B12 (or any other biomarker of B-complex vitamins) and BMD was observed in women. Based on the findings of this study, the authors highlight the protective role of vitamin B12 in bone health, especially in individuals with celiac disease. However, since the study was done exclusively in patients with celiac disease, it would not be possible to extrapolate these findings to a healthy population.

In a recent work by Bailey et al., ${ }^{13}$ serum levels of vitamin B12 were not directly associated with BMD, but the main functional indicator of this vitamin, methylmalonic acid, as well as serum homocysteine levels, were significantly associated with the risk of developing osteoporosis.

Holstein et al. ${ }^{14}$ concluded that only markers of bone formation (osteocalcin) were increased in individuals who had higher serum levels of B-complex vitamins, including B12. However, in the same study, no significant differences were found in the trabecular thickness of individuals with high and low serum levels of vitamin B12, thus questioning the true role of vitamin B12 in the turnover of bone biomarkers. It should be noted that this study involved patients diagnosed with osteoarthritis. The bone properties of those suffering from this disease may differ from those of the healthy population.

In a study by Bozcurt et al., ${ }^{15}$ postmenopausal women with low BMD in the femoral neck and in the vertebrae had significantly lower serum levels of vitamin B12. Also, homocysteine levels were higher in women diagnosed with osteoporosis than in normal or osteopenic patients.

Baines et al. ${ }^{16}$ stated that the risk of osteoporosis in postmenopausal women was associated with a reduced folate concentration and increased homocysteine concentration in the blood. Although there was no significant association between vitamin B12 and BMD in this study, reduced serum levels of vitamin B12, B6 and folate were associated with an increase in plasma homocysteine concentrations and adverse effects on bone health. Rumbak et al. ${ }^{17}$ in turn, stated that among healthy women, regardless of menopausal status, aged 45-65 years, there was insufficient evidence that vitamin B12, homocysteine or folate levels were related to BMD.

Physiologically, in humans, vitamin B12 acts as an essential cofactor for two enzymes: methionine synthase and L-methylmalonyl-CoA mutase, both directly and

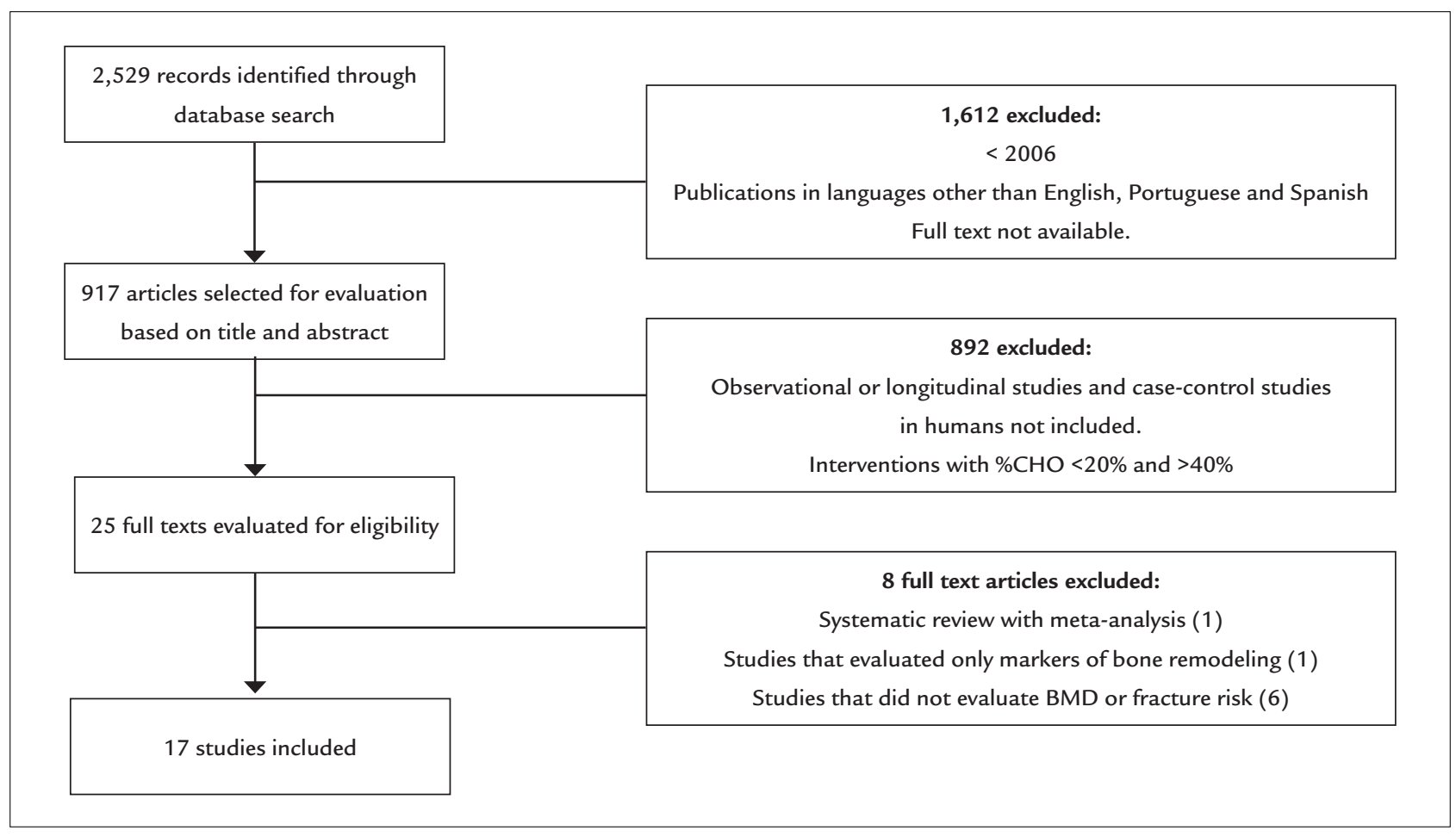

FIGURE 1 Flowchart of the studies evaluated for eligibility and included in the review. 


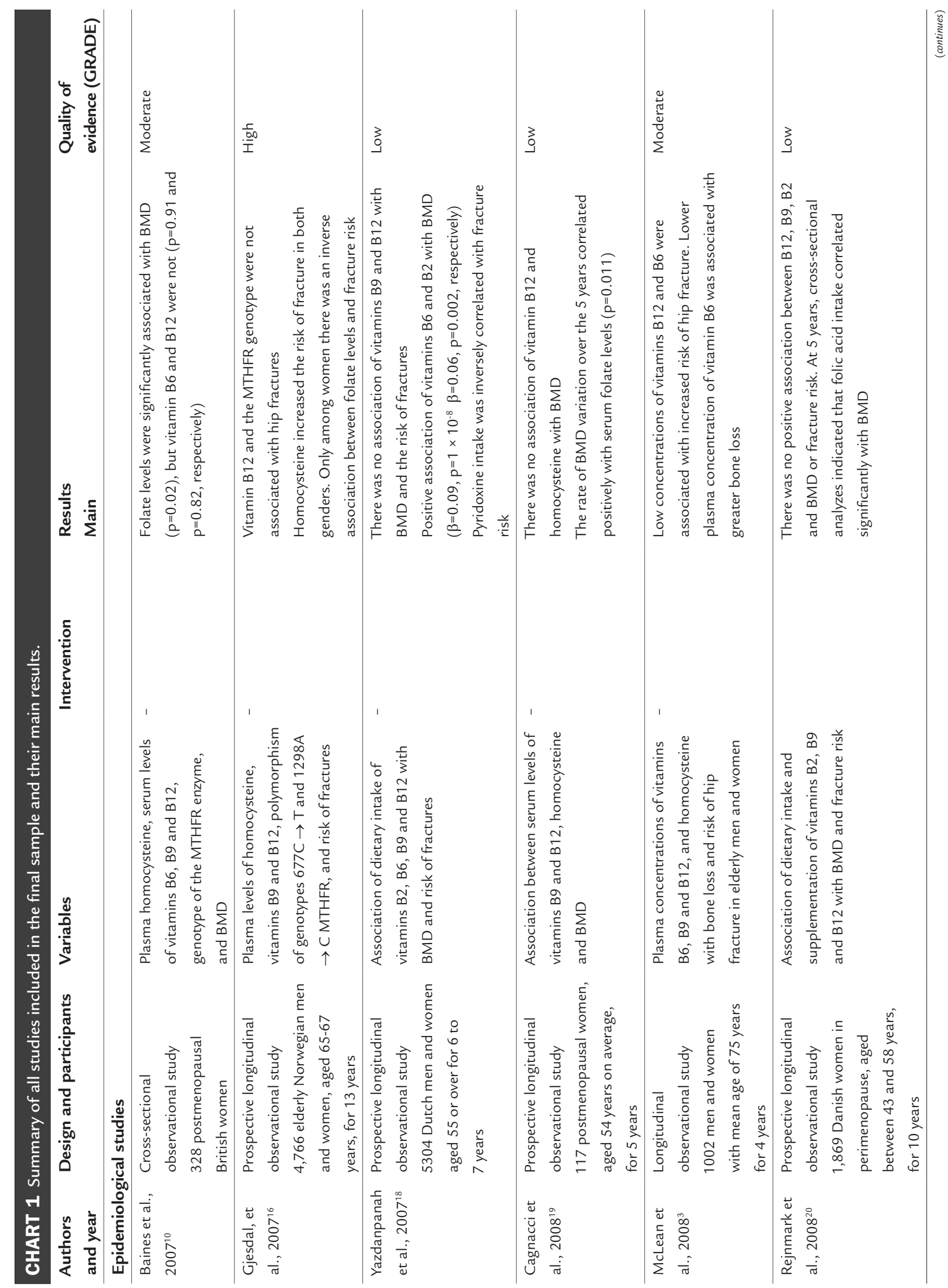




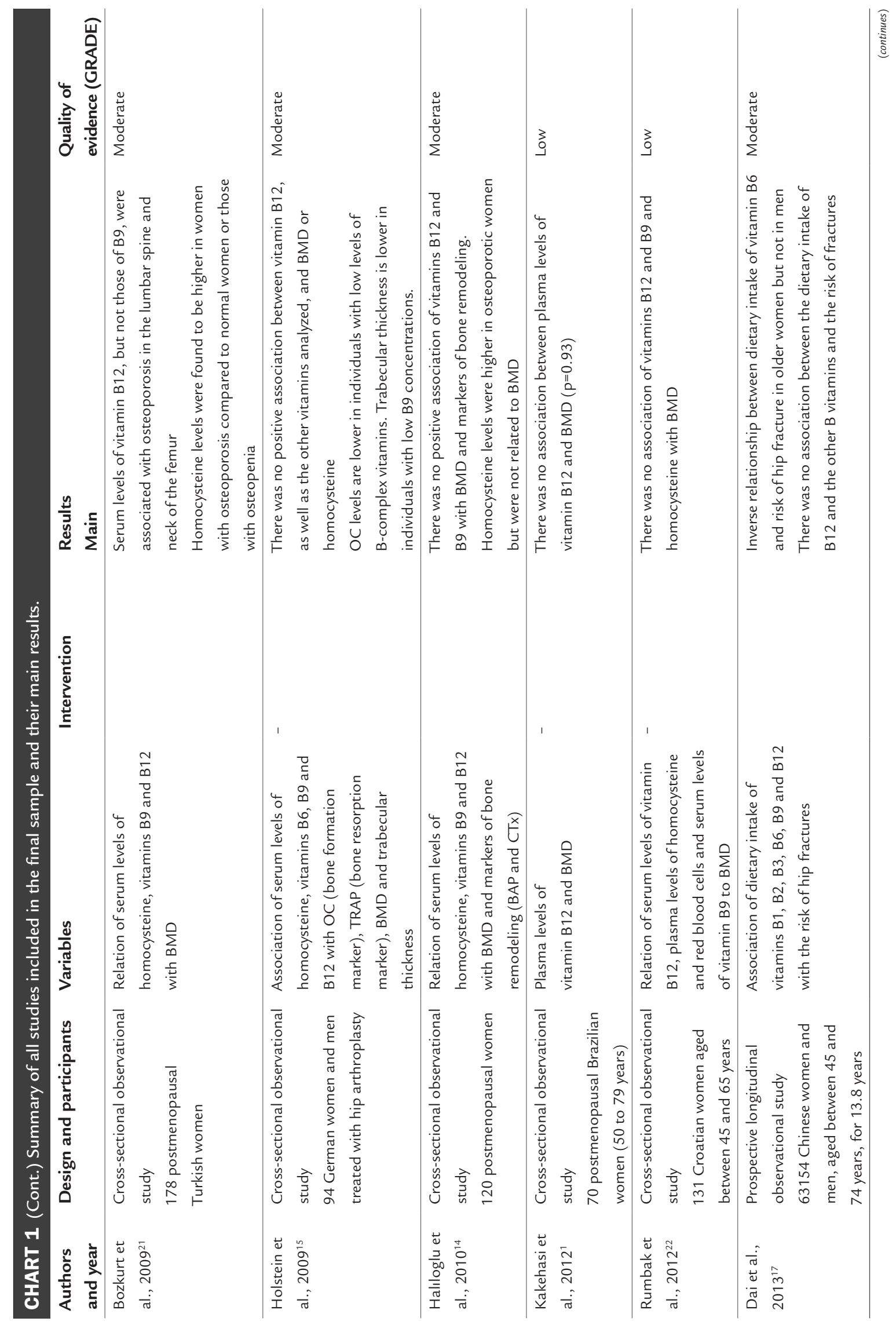




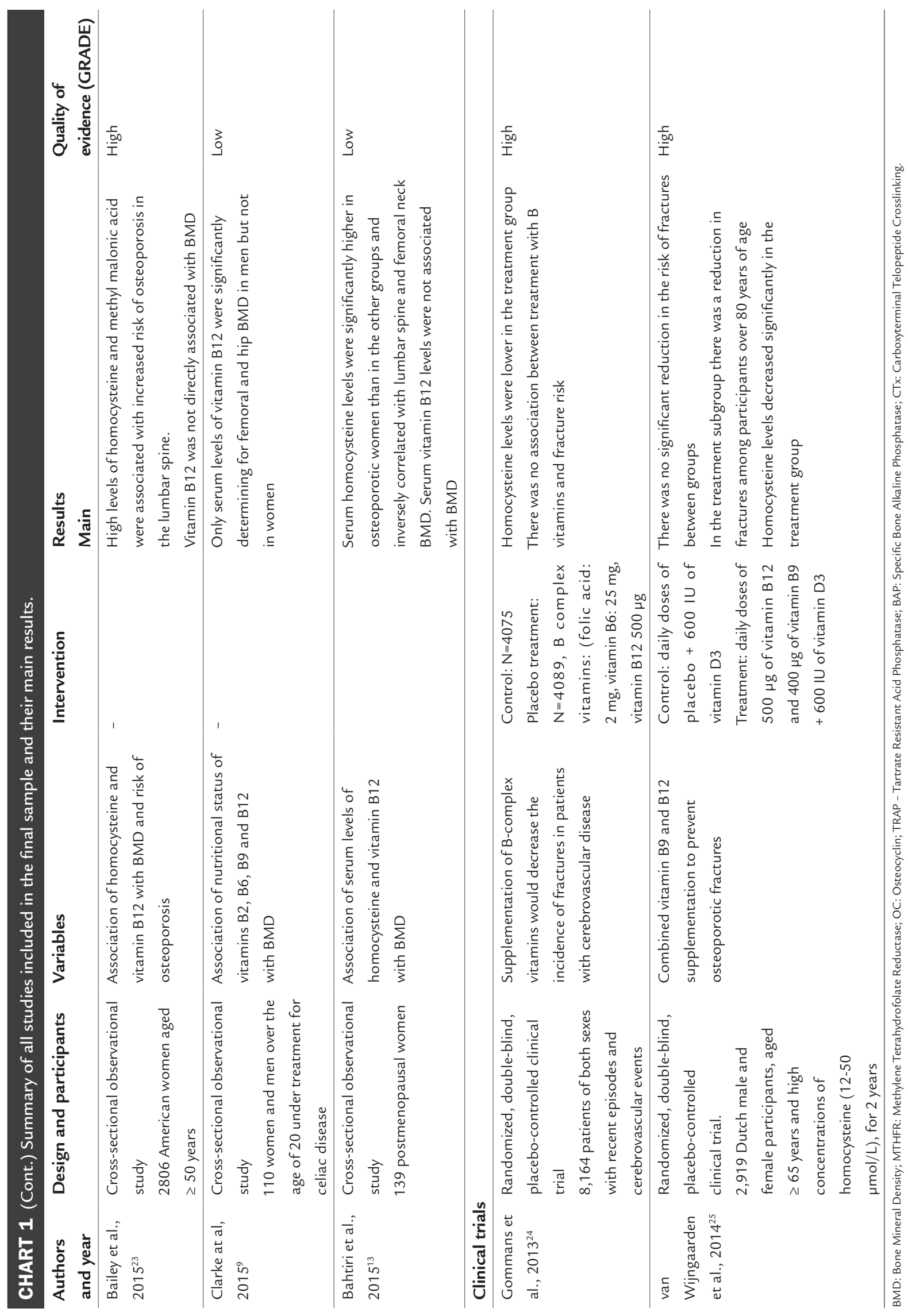


indirectly involved in the metabolism of homocysteine (Hcy) and methyl malonic acid (MMA), two functional biomarkers of vitamin B12 deficiency. ${ }^{26}$ Methylmalonic acid is a sensitive marker for vitamin B12 deficiency. ${ }^{27}$

Low levels of vitamin B12 in conjunction with folate and vitamin B6 deficiency are closely related to the metabolism of homocysteine (Hcy). Hyperhomocysteinemia is associated with increased markers of bone remodeling and, consequently, increased risk of fracture. Thus, hyperhomocysteinemia caused by deficiency of vitamin B12 as well as folate may be considered as new risk factors for osteoporosis related to the deficiency of these micronutrients. ${ }^{18,28}$

During perimenopause, there is an increase in the rate of remodeling and loss of bone mass at each cycle of remodeling, caused by the decrease in circulating levels of estrogen. ${ }^{29}$ In addition, homocysteine levels, also linked to osteoporosis and fractures, ${ }^{13,16,18}$ are higher in postmenopausal women, ${ }^{30,31}$ and are inversely related to folate levels and possibly vitamin B12, two essential cofactors for remethylation to methionine. The other cross-sectional studies with postmenopausal women in our review found no association between serum or plasma levels of vitamin B12 and BMD. .,22,24

Six longitudinal studies with large population cohorts were included. Of these, only one found association of vitamin B12 with BMD. McLean et al. ${ }^{3}$ concluded that low concentrations of vitamins B12 and B 6 were associated with increased risk of hip fracture and the risk remained high even after adjusting for homocysteine and BMD. In that same study, individuals who were grouped as vitamin B12 deficient had a greater tendency to lose bone mass compared to the group of individuals who had higher vitamin B12 concentrations.

In agreement with these findings, the Framignham Osteoporosis study, developed with the participation of 2,576 American men and women, found a positive relation between serum vitamin B12 levels $(<148 \mathrm{pg} / \mathrm{mL})$ and hip $\mathrm{BMD}$ in men and vertebral BMD in women. These results corroborate the information that vitamin B12 is a modifiable risk factor for the prevention of osteoporosis. ${ }^{32}$ Morris et al..$^{33}$ also found evidence in which vitamin B12 status indicators (serum levels and methylmalonic acid) and serum homocysteine levels were associated with BMD in American men and women $(\mathrm{n}=1,550)$ over 55 years of age.

Neither Yazdanpanah et al., ${ }^{19}$ Rejnamark et al. ${ }^{21}$ or Dai et al. ${ }^{23}$ found any association between dietary intake of vitamin B12 and bone mineral density and/or risk of fractures. It should be noted that cobalamin levels were verified through food surveys (food frequency questionnaires and food registry). There was no analysis of serum levels of B vitamins to assess the actual nutritional status of vitamin B12. It is noteworthy that such a result of the dietary intake of this vitamin could be biased because it is self-reported.

A study by Gjesdal et al. ${ }^{18}$ with a high level of evidence according to the GRADE score showed no association between plasma levels of vitamin B12 and the risk of hip fractures.

None of the two randomized, double-blind, placebocontrolled trials in our review found evidence of a positive effect of vitamin B12 (and other B-complex vitamins) supplementation on the risk or incidence of osteoporotic fractures. In both studies, serum homocysteine levels were lower in the groups receiving B complex supplementation (Chart 1), but there was no reduction in fracture risk between the control and treatment groups. ${ }^{25,34}$

The experimental trials are also contradictory regarding the action of vitamin B12 on bone tissue. The direct action of vitamin B12 on osteoblasts was observed, based on the functional and dose-dependent proliferative response found when two osteosarcoma cell lines were stimulated with cyanocobalamin. ${ }^{6}$ While investigating the impact of vitamin B12 and folate deficiency on the healing of fractures in mice, although hyperhomocysteinemia was detected in this group, there were no changes in bone repair in the context of this nutritional alteration..$^{35}$ Taken together, the experimental data from these studies are of potential clinical relevance, despite using different experimental models.

In the randomized study of B-Probe intervention (2,919 participants $\geq 65$ years) who underwent exploratory subgroup analyzes involving people over 80 years of age, combined vitamin B12 and folic acid supplementation had a beneficial effect in preventing osteoporotic fractures. However, another outcome found in this study was the association of treatment with the increased incidence of cancer, recommending caution regarding the supplementation of these vitamins in the elderly. ${ }^{34}$

\section{Conclusion}

The association between vitamin B12 levels, low bone mineral density and risk of fractures has been described in the literature, but the studies are quite heterogeneous and the results are contradictory. So far, the actual impact of vitamin B12 deficiency on bone health and the mechanisms associated with bone metabolism are not well established. Further studies are of paramount importance, especially in vulnerable groups such as postmenopausal women and elderly individuals, both greatly affected by vitamin deficiency. This also reinforces the relevance of 
identifying individuals who may benefit from appropriate therapy intervention in time to reduce morbidity and mortality associated with decreased bone mineral density.

\section{Resumo}

Vitamina B12, densidade mineral óssea e risco de fraturas em adultos: uma revisão sistemática

Objetivo: Consolidar as informações disponíveis acerca dos efeitos da vitamina B12 sobre a densidade mineral óssea e o risco de fraturas, com destaque para ensaios clínicos, dados observacionais e longitudinais realizados com humanos.

Método: Foi realizada uma revisão sistemática da literatura dos últimos dez anos sobre o papel da vitamina B12 na densidade mineral óssea e no risco de fraturas em populações de todas as idades e para ambos os sexos, com busca de artigos nos bancos de dados eletrônicos: PubMed, Science Direct, Medline e SciELO. Como estratégia de busca de dados incluíram-se os descritores: B12 Vitamin and Bone Mineral Density e B12 Vitamin and Risk of Fractures. A qualidade das evidências dos artigos incluídos foi avaliada pelo sistema GRADE.

Resultados: Após a análise dos títulos e dos resumos dos artigos, a estratégia de busca resultou em 25 referências, das quais 17 artigos preencheram os critérios de elegibilidade. Esta revisão fornece evidências de que o papel da vitamina B12 sobre a densidade mineral óssea ou o risco de fraturas ainda precisa ser mais bem elucidado. As controvérsias encontram respaldo na heterogeneidade das metodologias utilizadas para o diagnóstico da vitamina B12 e também na variedade de populações presentes entre os estudos.

Conclusão: Ainda não está bem estabelecido o real impacto da deficiência de vitamina B12 na saúde dos ossos e sobre os mecanismos associados ao metabolismo ósseo. É de suma importância a realização de mais estudos esclarecedores, principalmente em grupos vulneráveis como as mulheres pós-menopausa e os idosos, grupos estes bastante afetados pela deficiência dessa vitamina.

Palavras-chave: saúde óssea, suplementação de vitamina B12, risco de fratura.

\section{RefEREnCES}

1. Kakehasi AM, Carvalho A V, Maksud FAN, Barbosa AJA. Serum levels of vitamin B12 are not related to low bone mineral density in postmenopausal Brazilian women. Rev Bras Reumatol. 2012; 52(6):858-69.

2. van Wijngaarden JP, Dhonukshe-Rutten RAM, van Schoor NM, van der Velde $\mathrm{N}$, Swart KM, Enneman AW, et al. Rationale and design of the B-PROOF study, a randomized controlled trial on the effect of supplemental intake of vitamin B12 and folic acid on fracture incidence. BMC Geriatr. 2011; 11:80.

3. McLean RR, Jacques PF, Selhub J, Fredman L, Tucker KL, Samelson EJ, et al. Plasma B vitamins, homocysteine, and their relation with bone loss and hip fracture in elderly men and women. J Clin Endocrinol Metab. 2008; 93(6):2206-12.

4. Roman-Garcia P, Quiros-Gonzalez I, Mottram L, Lieben L, Sharan K, Wangwiwatsin A, et al. Vitamin B 12-dependent taurine synthesis regulates growth and bone mass. J Clin Invest. 2014; 124(7):2988-3002.

5. Dai Z, Koh W-P. B-vitamins and bone health - A review of the current evidence. Nutrients. 2015; 7(5):3322-46.

6. Kim GS, Kim C-H, Park JY, Lee K-U, Park CS. Effects of vitamin B12 on cell proliferation and cellular alkaline phosphatase activity in human bone marrow stromal osteoprogenitor cells and UMRI06 osteoblastic cells. Metabolism. 1996; 45(12):1443-6.

7. Bailey RL, van Wijngaarden JP. The role of B-vitamins in bone health and disease in older adults. Curr Osteoporos Rep. 2015; 13(4):256-61.

8. Ebesunun MO, Umahoin KO, Alonge TO, Adebusoye LA. Plasma homocysteine, B vitamins and bone mineral density in osteoporosis: a possible risk for bone fracture. Afr J Med Med Sci. 2014; 43(1):41-7.

9. Clarke M, Ward M, Dickey W, Hoey L, Molloy AM, Waldron L, et al. B-vitamin status in relation to bone mineral density in treated celiac disease patients. Scand J Gastroenterol. 2015; 50(8):975-84.

10. Atkins D, Best D, Briss PA, Eccles M, Falck-Ytter Y, Flottorp S, et al.; Grade Working Group. Grading quality of evidence and strength of recommendations. BMJ. 2004; 328(7454):1490.

11. Goerss JB, Kim CH, Atkinson EJ, Eastell R, O’Fallon WM, Melton III LJ. Risk of fractures in patients with pernicious anemia. J Bone Miner Res. 1992; 7(5):573-9.

12. Melton ME, Kochman ML. Reversal of severe osteoporosis with vitamin B12 and etidronate therapy in a patient with pernicious anemia. Metabolism. 1994; 43(4):468-9.

13. Bailey RL, Looker AC, Lu Z, Fan R, Eicher-Miller HA, Fakhouri TH, et al. B-vitamin status and bone mineral density and risk of lumbar osteoporosis in older females in the United States. Am J Clin Nutr. 2015; 102(3):687-94.

14. Holstein JH, Herrmann M, Splett C, Herrmann W, Garcia P, Histing T, et al. Low serum folate and vitamin B-6 are associated with an altered cancellous bone structure in humans. Am J Clin Nutr. 2009; 90(5):1440-5.

15. Bozkurt N, Erdem M, YIlmaz E, Erdem A, Biri A, Kubatova A, et al. The relationship of homocyteine, B12 and folic acid with the bone mineral density of the femur and lumbar spine in Turkish postmenopausal women. Arch Gynecol Obstet. 2009; 280(3):381-7.

16. Baines M, Kredan MB, Usher J, Davison A, Higgins G, Taylor W, et al. The association of homocysteine and its determinants MTHFR genotype, folate, vitamin B12 and vitamin B6 with bone mineral density in postmenopausal British women. Bone. 2007; 40(3):730-6.

17. Rumbak I, Zižić V, Sokolić L, Cvijetić S, Kajfež R, Colić Barić IC. Bone mineral density is not associated with homocysteine level, folate and vitamin B12 status. Arch Gynecol Obstet. 2012; 285(4):991-1000.

18. Gjesdal CG, Vollset SE, Ueland PM, Refsum H, Meyer HE, Tell GS. Plasma homocysteine, folate, and vitamin B12 and the risk of hip fracture: the hordaland homocysteine study. J Bone Miner Res. 2007; 22(5):747-56.

19. Yazdanpanah N, Zillikens MC, Rivadeneira F, de Jong R, Lindemans J, Uitterlinden AG, et al. Effect of dietary B vitamins on BMD and risk of fracture in elderly men and women: the Rotterdam Study. Bone. 2007; 41(6):987-94

20. Cagnacci A, Bagni B, Zini A, Cannoletta M, Generali M, Volpe A. Relation of folates, vitamin B12 and homocysteine to vertebral bone mineral density change in postmenopausal women. A five-year longitudinal evaluation. Bone. 2008; 42(2):314-20

21. Rejnmark L, Vestergaard P, Hermann AP, Brot C, Eiken P, Mosekilde L. Dietary intake of folate, but not vitamin B2 or B12, is associated with increased bone mineral density 5 years after the menopause: results from a 10 -year follow-up study in early postmenopausal women. Calcif Tissue Int. 2008; 82(1):1-11.

22. Haliloglu B, Aksungar FB, Ilter E, Peker H, Akin FT, Mutlu N, et al. Relationship between bone mineral density, bone turnover markers and homocysteine, folate and vitamin B12 levels in postmenopausal women. Arch Gynecol Obstet. 2010; 281(4):663-8.

23. Dai Z, Wang R, Ang LW, Yuan JM, Koh WP. Dietary B vitamin intake and risk of hip fracture: the Singapore Chinese Health Study. Osteoporos Int. 2013; 24(7):2049-59. 
24. Bahtiri E, Islami H, Rexhepi S, Qorraj-Bytyqi H, Thaçi K, Thaçi S, et al. Relationship of homocysteine levels with lumbar spine and femur neck BMD in postmenopausal women. Acta Reumatol Port. 2015; 40(4):355-62.

25. Gommans J, Yi Q, Eikelboom JW, Hankey GJ, Chen C, Rodgers H; VITATOPS trial study group. The effect of homocysteine-lowering with B-vitamins on osteoporotic fractures in patients with cerebrovascular disease: substudy of VITATOPS, a randomised placebo-controlled trial. BMC Geriatr. 2013; 13:88.

26. Hoey L, Strain JJ, McNulty H. Studies of biomarker responses to intervention with vitamin B-12: a systematic review of randomized controlled trials. Am J Clin Nutr. 2009; 89(6):1981S-96S.

27. Chatthanawaree W. Biomarkers of cobalamin (vitamin B12) deficiency and its application. J Nutr Heal Aging. 2011; 15(3):227-31.

28. Herrmann M, Widmann T, Colaianni G, Colucci S, Zallone A, Herrmann W. Increased osteoclast activity in the presence of increased homocysteine concentrations. Clin Chem. 2005; 51(12):2348-53.

29. Riggs BL, Khosla S, Melton LJ 3rd. A unitary model for involutional osteoporosis: estrogen deficiency causes both type I and type II osteoporosis in postmenopausal women and contributes to bone loss in aging men. J Bone Miner Res. 1998; 13(5):763-73.
30. Rasmussen LB, Ovesen L, Bulow I, Knudsen N, Laurberg P, Perrild H. Folate intake, lifestyle factors, and homocysteine concentrations in younger and older women. Am J Clin Nutr. 2000; 72(5):1156-63.

31. Bruschi F, Daguati R, Parazzini F, Dal Pino D, Fiore V, Di Pace R, et al. Age, menopausal status and homocysteine levels in women around menopause. Eur J Obstet Gynecol Reprod Biol. 2005; 120(2:)195-7.

32. Tucker KL, Hannan MT, Qiao N, Jacques PF, Selhub J, Cupples LA, et al. Low plasma vitamin B12 is associated with lower BMD: the Framingham Osteoporosis Study. J Bone Miner Res. 2005; 20(1):152-8.

33. Morris MS, Jacques PF, Selhub J. Relation between homocysteine and B-vitamin status indicators and bone mineral density in older Americans. Bone. 2005; 37(2):234-42.

34. van Wijngaarden JP, Swart KMAA, Enneman AW, Dhonukshe-Rutten RA, van Dijk SC, Ham AC, et al. Effect of daily vitamin B-12 and folic acid supplementation on fracture incidence in elderly individuals with an elevated plasma homocysteine concentration: B-PROOF, a randomized controlled trial. Am J Clin Nutr. 2014; 100(6):1578-86.

35. Holstein JH, Herrmann M, Schmalenbach J, Obeid R, Olkü I, Klein M, et al. Deficiencies of folate and vitamin B12 do not affect fracture healing in mice. Bone. 2010; 47(1):151-5. 